\title{
DE SASTRES A IDEÓLOGOS: \\ MOVILIZADORES DE IDEAS A FINALES DEL SIGLO XIX Y \\ COMIENZOS DEL XX.
}

\author{
FROM TAILORS TO IDEOLOGISTS: \\ IDEAS PROMOTERS LATE XIX CENTURY AND EARLY XX \\ CENTURY.
}

RESUMO: El objetivo de este texto es describir la forma en la que los sastres Antonio Guedes Coutinho de Brasil e Ignacio Torres Giraldo de Colombia se transformaron en importantes articuladores de ideas de izquierda durante las últimas décadas del siglo XIX y comienzos del siglo XX. El texto se divide en cuatro secciones en las que se abordan: los contextos históricos de estos líderes obreros, la composición de las ideas de izquierda a partir de la concepción de libertad, las formas en que fueron apropiadas retóricamente estas ideas, y una conclusión en la que se presentan las diferencias y las similitudes de las actuaciones de los dos líderes obreros, quienes progresivamente se convirtieron en ideólogos de las clases obreras y populares.

PALAVRAS-CHAVE: Ideas. Izquierda. Líderes. obreros.

ABSTRACT: The purpose of this paper is to describe the form in which the tailors Antonio Guedes Coutinho from Brazil and Ignacio Torres Giraldo from Colombia become important left ideas promoters during the last decades of century XIX and the beginning of century XX. The text is divided into four parts corresponding to: the historical contexts of these laborer leaders, the composition of left ideas from liberty conception, the forms in which these ideas were appropriated rhetorically, and a conclusion in which differences and correspondences of the laborer leaders acts are exposed, in order to demonstrate that they became ideologist of working and popular classes.

KEY WORDS: Ideas . Left. Laborer. leaders.

Las ideas construyen conexiones imaginarias, juegan con los contextos y desconocen el devenir sincrónico del tiempo. Aunque esta afirmación parece radical, no significa que las ideas deban ser entendidas como entidades innatas o perpetuas. Por el contrario, las ideas se nutren de los contextos socioculturales y de las condiciones materiales de existencia de los sujetos que las desarrollan y practican, formando un movimiento de apropiación que transgrede las dicotomías simplistas entre "elite-pueblo"; "intelectual-masa" o "episteme- 
doxa". Las ideas circulan y se convierten en el motivo "invisible" de las sociedades, ellas se mezclan con su tiempo y con los tiempos de los hombres al punto que son despojadas de sus “dueños originales" y se presentan como conexiones imaginarias entre la realidad material y las esperanzas que las sociedades tienen del futuro. Sin embargo, en medio de esa compleja apropiación, en la que las ideas son adaptadas a los contextos, sus características generales permiten entablar relaciones entre las diversas formas de actuación de los sujetos inspirados en ellas. La intención de este texto es entablar este tipo de relación, describiendo la actitud de dos sujetos que, a finales del siglo XIX y comienzos del siglo $\mathrm{XX}$, se convirtieron en complejos articuladores de ideas.

Las ideas fuerza o ideas-unidad (Lovejoy, 1936) a las cuales hago referencia, y que guiaron a los sujetos protagonistas de esta historia, son ideas que en su constante construcción y reconstrucción en distintos contextos dieron fuerza y sentido a las acciones de los individuos y las colectividades. En específico, este texto se centra en la idea de libertad que, para finales del siglo XIX y comienzos del siglo XX, se convirtió en el objetivo de las acciones planeadas en pleno ejercicio de la razón por los diferentes movimientos obreros, sus líderes e intelectuales.

Colocando la libertad en el horizonte de la retórica, los líderes obreros y populares de la época sustentaron sus acciones y apelaciones sobre la triada compuesta por la unión solidaria, la educación y la resistencia como el mejor camino para alcanzarla. Estos tres preceptos, progresivamente, se configuraron en el elemento articulador de las prácticas de la izquierda, pues los caminos planeados, tanto por los socialistas como por los anarquistas y comunistas, tuvieron como objetivo alcanzar el reino de la libertad tras la puesta en práctica de una serie de acciones que les permitió reivindicar su condición de clase.

Bajo esta perspectiva, las relaciones que propongo establecer, en el plano de las ideas, pretenden responder a dos preguntas: 1] ¿Cómo se presentaron, al interior de los movimientos obreros y populares de Colombia y Brasil las ideas de unión solidaria, educación y resistencia durante el periodo abordado? Y 2] ¿Qué papel jugaron los líderes obreropopulares Antonio Guedes Coutinho de Brasil e Ignacio Torres Giraldo de Colombia en la movilización y difusión de estas ideas? Las siguientes páginas, entonces, intentaran dar

\footnotetext{
${ }^{1}$ Estas dicotomías responden a la visión "clásica" de la historia de las ideas que privilegia el estudio de los maîtres à penser y las grandes teorías, desconociendo los contextos de producción y las condiciones de posibilidad de las ideas para constituirse en bienes simbólicos de determinados grupos sociales. Bajo esta perspectiva, intento separarme de esa lógica y centrarme en una historia social de las ideas que rescate la relación significado-contexto (meaning and context).
} 
respuesta a estas preguntas, estableciendo, como ya lo dije, relaciones entre dos contextos a partir de una serie de ideas comunes.

Durante las primeras décadas del siglo XX Colombia se caracterizó por ser una sociedad políticamente dividida. Los partidos Liberal y Conservador se disputaron el poder durante buena parte del siglo XIX y todo el siglo XX. Sus cuadros dirigentes eran hijos de una misma élite agraria y de burgueses provincianos, la principal diferencia entre unos y otros fue, principalmente, el papel que debía desempeñar la iglesia dentro de la organización del Estado. Entre los años de 1886 y 1930 el Partido Conservador tuvo el control político, durante este período, los conservadores gobernaron de manera ininterrumpida, consolidando un Estado centralista y conservador que dio a la iglesia el poder para la formación moral y la regulación cultura de la población. A este momento se le llamó en la historia política colombiana la Hegemonía Conservadora.

En términos económicos Colombia fue una sociedad poco desarrollada industrialmente, su principal motor económico fue la exportación de café y el sector agropecuario. Solo hasta bien entrada la década de los veinte los gobiernos conservadores incentivaron un lánguido desarrollo industrial gracias a la danza de los millones ${ }^{2}$, el flujo de créditos externos, la misión del profesor Kremmerer $^{3}$ y los buenos precios del café. Con esto, en la década de los veinte el desarrollo económico de Colombia se ubicó en tres escenarios distintivos: Los epicentros regionales de desenvolvimiento industrial, donde apareció una prematura clase obrera ligada a los textiles y la fabricación de cervezas; el sector de obras públicas, relacionado con la expansión de las vías férreas, carreteras y el transporte fluvial; y finalmente, los enclaves imperialistas, en los cuales se explotaron los recursos naturales del país y en los que se mezclaron el capital extranjero y las constantes omisiones de una élite nacional sumisa. Este último espacio se destacó por generar una clase obrera fuertemente combativa.

En este contexto, marcado por el surgimiento de una incipiente clase obrera, actuaron los principales líderes de las clases populares. Progresivamente, la clase obrera de Colombia

\footnotetext{
${ }^{2}$ Se refiere a los 25 millones de dólares que los Estados Unidos pagaron al gobierno colombiano en la década del veinte por la pérdida del canal de Panamá en 1903.

3“"La presencia de una misión financiera, presidida por el profesor E. Kremmerer, favoreció el otorgamiento de créditos desde 1923 y dio pautas para la reforma del sistema fiscal, la creación de un banco central emisor y la reorganización de los ministerios.” (ARCHILA, 1991, p.48) Ver también (VEGA,2002)
} 
inició su proceso de constitución bajo el ritmo impuesto por el desplazamiento del campo a las ciudades medianamente industrializadas. Con las características de una población campesina, la clase obrera que se aglomeró en las nuevas ciudades se enfrentó al problema del crecimiento descontrolado de las urbes y a la rápida modificación de los contextos socioculturales. "La cuestión social" apareció con la discriminación, los cinturones de miseria, el aumento del costo de vida y la escasez. La única forma en la que los obreros pudieron resistir a su realidad fue utilizando las herramientas heredadas del movimiento artesano y la fe cristiana del campesino, encarnadas en tres tradiciones ${ }^{4}$ bien definidas: Los elementos de religiosidad popular, el radicalismo liberal hijo de la revolución francesa y la preocupación por lo social (Archila, 1991, p. 88- 95; Vega, 2002, p.150-ss; Núñez, 2006, p.87-100).

En esas circunstancias, en las que se mezclaron las tradiciones campesinas y artesanas con los primeros brotes de capitalismo, el joven aprendiz de sastre Ignacio Torres Giraldo inició su carrera como líder obrero y popular. Torres nació en el departamento de Quindío en Colombia, el 5 de mayo de 1893. Hijo de una familia humilde, siendo aún joven se vinculó al oficio de sastre con el objetivo de tener mayor autonomía y tiempo para el estudio. Se vinculó al mundo de los artesanos y obreros participando en diversas reuniones y discusiones referentes a la organización y reivindicación del oficio. Lector asiduo, Torres se fue convirtiendo, de manera autodidacta, en un intelectual de su medio. Pedía libros prestados de la única biblioteca de Pereira donde vivió su infancia, y con gran esfuerzo aprendió a leer y escribir por su cuenta a los 16 años de edad. En 1904, por medio de una conferencia sobre socialismo de Estado pronunciada por el general Rafael Uribe Uribe -liberal radical de la época-, Girado encuentra información sobre el movimiento obrero internacional, y gracias a las conversaciones con los jóvenes inconformes de su época, las contradicciones sociales fueron develándose más claras para el joven autodidacta.

En 1911, según el propio sastre colombiano, ya leía a algunos autores socialistas franceses e italianos y prestaba especial atención a ensayos argentinos y chilenos que “expresaban interés por los problemas sociales" (TORRES, 2005, p.6). De este modo, influenciado por el socialismo utópico, las lecturas moralistas de Tolstoi, la americanidad de Gabriela Mistral y las enseñanzas de Rodó, Torres llevó la idea de libertad a los oídos de los obreros y las gentes pobres de Colombia. En 1916, por ejemplo, escribió en un tono apocalíptico y con sobrada temeridad - como él mismo decía-, que si los burgueses que

${ }^{4}$ Más referencias sobre esta herencia de las tradiciones ver: AGUILERA \& VEGA, 1998 
manejan al país no caían "cuando los rayos justicieros del hacedor del universo se envíen al pedazo miserable de tierra colombiana [...] no existe Dios" ${ }^{5}$, intentando unir una necesidad de transformación, con un principio teológico de justicia divina, propio de la cultura popular de la época.

En el año de 1914 sus posicionamientos políticos e ideológicos tomaron un carácter más definido tras el estallido de la primera guerra mundial y el asesinato del socialista francés Jean Jaurés. Para esta época, según Torres, ya podía ser considerado un socialista utópico (TORRES, 2005, p.7). Después de la Revolución Rusa de 1917, Torres se sintió atraído, como muchos líderes obreros de la época en América Latina, por las filas del pueblo bolchevique, y en el marco de la difusión de la literatura socialista entre 1918 y 1919 leyó apasionadamente "El capital que abrevió Devill, El origen de la familia, la propiedad privada y Estado de Federico Engels y diversas obras de autores también notables [...]” (TORRES, 2005, p.9).

Unas décadas antes, en un contexto marcado por la inmigración europea, y la rápida aparición de la clase obrera "organizada", bajo los ejemplos de los movimientos obreros europeos, actuó el sastre portugués Antonio Guedes Coutinho. Utilizando el periódico Echo Operário como vehículo de conexión con el proletariado de una apartada región del sur de Brasil, el sastre portugués escribió salves apasionados a la libertad de los obreros, y confió en el papel del conocimiento para la "salvación" de los obreros. "Salve! Aurora de liberdade! Que a tua luz dissipe as trevas da ignorância e martírio, e os fulgores de tua mágica influência fulminem os retrógrados incapazes de compreender-te" 6 .

Según el historiador norteamericano Joseph Love (1997), al iniciar el siglo XX Rio Grande do Sul, región de actuación de Coutinho, era una anomalía en el contexto nacional de Brasil, ya que: “[...] economicamente não se orientou [...] nem para a exportação nem para a subsistência; politicamente não foi nem um Estado dominante nem um Estado satélite" (1997, p.99). La economía del estado sureño se basó principalmente en el ganado, la producción de carne y una industria de pequeña escala, configurando una economía dinámica e importante para la Unión. En este contexto la población riograndense inició un rápido período de crecimiento que, sumado a la expansión de las ciudades y al surgimiento de las primeras fábricas, generó -al igual que Colombia, unos años más tarde- la explosión de la cuestión social.

El problema causado por la elevación de los precios en las ciudades, la miseria y la explotación de las primeras fábricas industriales, permitió la rápida creación de un

\footnotetext{
${ }^{5}$ El Martillo, No. 1, 1916, Apud ARCHILA (1999 p. 90).

${ }^{6}$ Echo Operario, 27/3/1898. p.1, Apud Schmidt (2000, p. 35)
} 
movimiento obrero en la región y posibilitó la aparición de un Partido Socialista, fundado en la ciudad de Rio Grande el 01 de mayo de 1898. Antonio Guedes Coutinho fue uno de los fundadores y miembro activo del movimiento socialista. Coutinho nació en la provincia de Tras-os-Montes en Portugal el día 13 de noviembre de 1868. En esta pequeña provincia portuguesa Coutinho aprendió, a parte de sus primeras letras, el oficio de sastre. Sin embargo, debido a la falta de oportunidades de trabajo y progreso, en 1886 el joven portugués tomó un barco rumbo al Brasil en busca de una mejor fortuna ${ }^{7}$.

Caracterizado como un insaciable lector, Coutinho vivió un período de transición entre el trabajo artesanal y la imposición de los ritmos de la fábrica. Así, sumergido en los ambientes ambivalentes de una intelectualidad artesanal, heredera de una tradición de disidencia, y el mundo de la organización obrera de la nueva sociedad de masas, Coutinho se interesó por aprehender las principales corrientes socialistas de la época. Con curiosidad de investigador, el portugués pretendió entender las formas en las que el patrón explotaba al trabajador imponiendo dinámicas diferentes en las que la prioridad era la producción de capital: "de um momento para outro, a rutina diária passou a não ser mais determinada pela claridade e pela escuridão, mas pelo apito da fabrica marcando os horários de trabalho e repouso" (SCHMIDT, 2000, p. 47). De esta manera, y bajo los incisivos análisis de su realidad y la de los obreros, Antonio Guedes Coutinho se transformó en la principal figura del socialismo del extremo sur del Brasil (Bartz, 2008).

\section{II}

La libertad es una idea fuerza que, según el intelectual ingles Isahiah Berlin (1981), se presenta peligrosa en su búsqueda, ya que fácilmente puede adquirir un carácter incontrolado y convertirse en un poder irresistible sobre las multitudes. Además, desde la idea de libertad se puede justificar cualquier tipo de acción -tanto positiva como negativa-. La libertad, en sí misma, es una idea arquetípica que tiene una multiplicidad de significados y sentidos (WALICKI, 1998). En palabras del escritor francés Paul Válery (1938, Apud, NOVAES, 2002, p.7), por ejemplo, la libertad es “[...] una de esas detestables palabras que tienen más valor que sentido" (trad. mía). Afirmación con la cual, de manera general, podemos concordar al comprobar el sentido ambiguo que la idea de libertad tuvo al comenzar el siglo XX. Sin embargo, aunque la libertad sea una de las ideas más complejas para definir, de dos cosas no

${ }^{7}$ Las informaciones de Coutinho fueron extraídas del trabajo de Schmit (2000). 
podemos dudar: Primero, que la libertad ha sido el motor de múltiples transformaciones históricas y luchas sociales, razón por la cual ninguna sociedad puede ser pensada sin encarar esta idea. Segundo, que la libertad se ha introducido en la historia de las sociedades, no por su abundancia sino por su privación. Al fin y al cabo, como sostiene Hannah Arendt, "los períodos de libertad han sido siempre relativamente breves en la historia de la humanidad" (1991, p.2). Fue así que la idea de libertad y su búsqueda consciente motivó la acción de muchos líderes de izquierda durante los primeros años del siglo XX. No obstante, ¿Cómo se materializaron los caminos a ella?

La libertad, en la retórica de la izquierda, fue representada en una compleja asociación de racionalidad y pasión. Una asociación que fue, además, perfectamente aprehendida al interior de las ideologías radicales de la época que movilizaban a los sujetos desde un lenguaje poético, racional, místico y profético. Siguiendo los principios de la razón socialista y el liberalismo radical, tanto Coutinho como Torres iniciaron su trabajo en el mundo del movimiento obrero y popular, con el fin de articular la idea de libertad.

De acuerdo con las teorías clásicas sobre la libertad, que la dividen entre Libertad Positiva y Libertad Negativa, se puede sostener que la libertad, como la asumieron los movimientos de izquierda de la época, se ubicó en el plano de la libertad positiva. Siguiendo la propuesta de Berlin (1981), la libertad positiva derivó del deseo del sujeto de ser dueño de sí mismo, en este caso el sujeto quiere ser movido por razones y propósitos que sean suyos y que vengan de su interior. De esta afirmación resultan dos presupuestos: 1] Que el uso de la razón engendra, por sí mismo, una posibilidad de libertad (no depender de otros). 2] Que yo puedo ser libre entre leyes, siempre y cuando esas leyes hayan sido propuestas y aceptadas por mí, por mi razón. En otras palabras, en el marco de la libertad positiva, defendida por nuestros sastres, para que el hombre pudiera ser libre en sociedad debía utilizar sus capacidades racionales para formular sus propias leyes y acatarlas racionalmente. No obstante, en términos generales, las diversas ideologías que defendieron la razón y la vanguardia como camino a la libertad asumieron que no todo hombre tenía la facultad de llegar a su "verdadero" yo, a su yo racional que, en algunos casos, se confundía con el yo colectivo. De este modo, el papel de líder se cargó de sentido, ya que éste se asumió como la vanguardia capaz de guiar al ignorante hacia su libertad ${ }^{8}$. Tras este objetivo, y en un contexto artesanalmente intelectualizado, tanto Torres como Coutinho pasaron de su modesto taller de sastres, a liderar el movimiento obrero y popular, articulando un discurso y unas prácticas en ${ }^{8}$ Según Berlin la utilización del lenguaje extraído del sentido de un yo racional colectivo lleva a reconocer que es
"posible, y en algunos momentos justificable, oprimir a los hombres en nombre de algún fin" (1958, p.9)

Oficina do Historiador, Porto Alegre, EDIPUCRS, v. 7, n. 2, jul./dez. 2014, p. 155-172. 
que la unión solidaria, la educación y la resistencia se convirtieron en los medios para llegar a la libertad racionalmente constituida.

III

Con una combinación de religiosidad y lucha, en el periódico La Humanidad, fundado por Torres en 1925, el sastre colombiano presentó la forma como debía ser asumida la unión solidaria entre las clases obreras y populares:

Hemos renunciado a nuestra herencia política para servir el evangelio de la Humanidad: todos los trabajadores son nuestros hermanos; queremos que todos los hombres trabajen para que ninguno deje de ser hermano nuestro; queremos que los hombres sean libres, pero antes queremos que se eduquen, que piensen, porque nunca es libre el hombre que no piensa. ${ }^{9}$

Bajo un tono familiar y litúrgico, Torres hizo referencia a la hermandad y a la educación como las únicas formas de alcanzar la libertad. De modo que, con las herramientas de la retórica Torres destacó una hermandad que solo podía ser consolidada en el marco de los designios de una teoría revolucionaria: “[...] la necesidad de vertebrar el movimiento proletario que se desarrollaba en el país, creando un organismo independiente de dirección centralizada y naturalmente definiendo por completo su orientación clasista." (TORRES, 2005, p.12).

A esta idea de actuación, evidentemente más politizada, en la que una vanguardia debía actuar sobre la clase obrera, antecedió una idea de unión que pretendía alejarse de los partidos y movimientos políticos tradicionales de las primeras décadas del siglo XX. En ese sentido, Torres propuso que los obreros se unieran en torno a un movimiento autónomo y común a sus intereses:

Los obreros [...] son generalmente honrados, parcos, buenos padres, buenos hijos, buenos hermanos, forman un gremio respetable [...] Hoy se trata de reunirlos, agremiarlos, ponerlos en contacto directo. Si es para fines sociales y económicos muy bien; si es para fines políticos y para hacer de ellos un rebaño de carneros para elecciones[...] no y mil veces no[...] nada de

${ }^{9}$ La Humanidad 16/4/1925 (Apud ARCHILA 1985, p.1). 
política, ni de poner a los obreros como peones para fomentar el fanatismo y la vagancia. ${ }^{10}$

Vemos que, haciendo un llamado a la hermandad revolucionaria, se intentó constituir una unión obrera y popular en la que la visión de los "sastres-intelectuales" se mezcló con la de los obreros a fin de alcanzar la tan anhelada sociedad sin explotación. En consonancia con Torres, en 1898 Antonio Guedes Coutinho escribió de manera visceral su sentimiento de hermandad revolucionaria:

Se não tivesse nascido num berço humilíssimo e ao abrir os olhos não tivesse visto um pai que vestia a blusa do operário; desejaria no dia de hoje esquecer o meu nascimento para poder me considerar irmão dessa falange colossal de proletários e unir a minha voz à sua para de coração gritar: Guerra à exploração! Viva o socialismo! ${ }^{11}$.

En este llamado pasional, Coutinho presentó a su público proletario una visión familiar llena de camaradería y desprendimiento. Además, abrió las puertas a la lucha que permitiría transformar la realidad social desde la hermandad, a pesar de que en muchas ocasiones ese camino estuvo determinado por los constantes arrestos, el desinterés de la misma clase y la represión de los patrones y el Estado.

De forma determinante las primeras organizaciones obrero-populares en Colombia trabajaron bajo la lógica de que la unión y la solidaridad eran fuentes básicas para el progreso social (NUÑEZ, 2006). Del mismo modo, para lo obreros brasileros la solidaridad fue primordial para la sobrevivencia de su movimiento, ya que con la solidaridad y el afecto también se reprodujeron los conocimientos políticos y teóricos que permitieron, en muchos casos, la apropiación de la lucha social (BILHÃO, 1999, p. 108-ss).

Sin embargo, cuando se habla de solidaridad entre las clases trabajadoras se debe tener en cuenta que esta fue concebida, por lo menos para Torres y Coutinho, bajo la forma de organización política y educación del proletariado. Es por esto que en el conjunto de ideas de los movimientos obreros, la necesidad de educar a la clase se convirtió en una constante. Para Coutinho, por ejemplo, "[...] a massa dos trabalhadores [...] deve ser orientada [através de] centros, de palestras e conferencias socialistas, onde vão a ouvir a palavra amiga e verdadeira dos companheiros mais educados [...]" (SCHMIDT, 1996, p.65).

${ }^{10}$ El Martillo, 17/11/1916 (Apud ARCHILA, 1999, p.384. grifo mio).

${ }^{11}$ Echo Operario, 1/5/1898, p.3 (Apud SCHMIDT, 2000, p.42)

Oficina do Historiador, Porto Alegre, EDIPUCRS, v. 7, n. 2, jul./dez. 2014, p. 155-172. 
Además de esto, esta idea de educación para la revolución, propia del pensamiento de izquierda de principios del siglo XX, estuvo cargada de un halo de superioridad política, que propuso a un pequeño grupo comandar el yo racional de la sociedad. La libertad estuvo medida por la actuación de este grupo que "sabía" el camino hacia ella. En esa coyuntura apareció, entonces, el espectro de la vanguardia, presentada como una necesidad para el movimiento obrero:

\begin{abstract}
O que nós entendemos por verdadeira luta é a instrução do povo fazendo-o ver claramente a mistificação absoluta de todo o existente, leva-lo por caminho seguro à compreensão de seus direitos, obrigá-lo a raciocinar, a conhecer por si as causas produtoras dos males que o afligem, concita-lo ao estudo, a analise e observação de tudo quanto tem relação com a vida das sociedades e dos indivíduos ${ }^{12}$.
\end{abstract}

En el caso de Torres, la necesidad de destacar el papel de la vanguardia obrera lo llevó a culpar al pueblo por su situación:

[...] el pueblo que hizo cuanto existe sobre la faz de la tierra no debe, no puede vivir con su miseria, besando sus cadenas y adulando a sus amos. Que se rebele. La esclavitud voluntaria no sólo es un crimen, es también una vergüenza: quien pudiendo no rompe sus cadenas, no sólo es un cobarde sino que las merece [...] el pueblo colombiano es un esclavo culpable, porque no se rebela ${ }^{13}$.

Este último fenómeno fue bien interpretado por los trabajos de Schmid (1996) para el caso de Coutinho, y por Archila (1999) para el caso de Torres. Según Schmidt los procesos formativos, en algunos casos, se encontraron precedidos de un "convite autoritario". Invitación en la que se sobre entiende la superioridad de un núcleo de vanguardia. Al respecto Coutinho escribió:

Os homens individualmente podem ser muito capazes de se dirigir e governar, mas coletivamente, hão de sempre precisar de alguém que reúna em si a vontade de todos os membros da coletividade; o que é preciso é que

${ }^{12}$ Echo Operario. (Apud SCHMIDT, 1996, p.65. grifo mio).

${ }^{13}$ La Humanidad 12/9/1925 (Apud ARCHILA, 1985, p.1). 
esta seja a mais pequena possível para que assim seja facilitada a execução da vontade de todos ${ }^{14}$.

Archila destaca la tendencia catequista que adoptaron los primeros núcleos socialistas y anarquistas para la predica de su nuevo "evangelio" durante este período de organización obrera. Esos primeros núcleos se sentían las vanguardias del proceso de redención de la clase obrera, "por eso, paradójicamente, con el fin de provocar la rebeldía popular, [los lideres] desarrollaron un discurso vanguardista que en la práctica despreciaba al pueblo, visto como un ente pasivo y manipulable por las clases dominantes" (Archila, 1999, p. 386). En el periódico La Humanidad se encuentran afirmaciones como la siguiente: "El hombre: he ahí al animal más cobarde en el reino animal. Se le roba y no protesta; se le esclaviza y calla; se le hambrea [sic] y adula; se le ahorca y pide perdón"15. Afirmación que Torres, como fundador del periódico, compartía.

No obstante, bajo esta perspectiva política, muy influenciada por el pensamiento socialista, aún inmaduro, de las últimas décadas del siglo XIX y los primeros años del XX, lo que queda en el horizonte es un inmenso interés por educar al pueblo. La intención fue dar a la clase obrera las herramientas para construir un discurso de sí mismos y de sus luchas, y la única forma para hacerlo fue la incentivación constantes de los procesos formativos. Era necesario, según Coutinho:

derramar a luz, é preciso que os socialistas não se cansem da tarefa, que a si mesmos impuseram; façam propaganda em jornais, abram escolas de ensino livre, publiquem panfletos, celebrem palestras, conferências, tudo enfim, que seja derramar a luz, porque o povo o que carece é disso $[\ldots]^{16}$.

Todo ese mecanismo discursivo se convirtió en una forma de hacer resistencia a una sociedad en transformación, en la que la visión de mundo de los artesanos, obreros y clases populares en general, estaba cambiando rápidamente. Pero, ¿qué se puede entender por resistencia? Según James Scott (2003) toda estructura de dominación genera mecanismos particulares de resistencia encarnados en prácticas, rituales y disfraces lingüísticos. Además, el contenido específico de la resistencia puede también impulsar la esperanza popular para la creencia en el "regreso de un profeta, o la celebración de héroes rebeldes o mártires"

\footnotetext{
${ }^{14}$ Echo Operario 7/8/1898, p.1.(Apud SCHMIDT, 2000, p.98).

${ }^{15}$ La Humanidad. 10/07/1926 (Apud ARCHILA, 1985, p.1)

${ }^{16}$ Echo Operario. 9/10/1898, p. 3. ( Apud, SCHMIDT, 2000, p.164).
} 
(SCOTT, 2003, p. 20). De este modo, se podría decir que el propio lenguaje empleado por nuestros sastres en sus escritos fueron, en sí mismos, ejercicios de resistencia contra una sociedad que, hasta el momento, desconocía la humanidad de las clases populares.

En el caso de Coutinho, el autor escribió algunos cuentos en los que expresó la resistencia a los mecanismos de control que la fábrica establecía. Con su lenguaje presentó la cotidianidad de un mundo obrero en el que la libertad era alcanzable:

[...] Minha cara, estou farto de apanhar frio no inverno e calor no verão debaixo daquele maldito teto de zinco e vidro, e sempre ameaçado de passar fome se deixo de trabalhar um dia, enquanto que o dono da fabrica sem nada fazer, levantando-se quando quer, comendo e gozando a seu bel-prazer [...]. Que leve o diabo a fabrica com todos os seus regulamentos escravocratas. (Apud, SCHMIDT, 2000, p.50).

Este ejercicio de escritura pone en evidencia dos cosas: 1] las exigencias del tiempo de trabajo, impuestas por las lógicas capitalistas, permitieron que los obreros pusieran en práctica diversas formas de resistencia, en las que la imaginación jugó un papel fundamental como escapatoria de la realidad. 2] el contexto exigió que los líderes obreros se apropiaran de un lenguaje "simple", que les permitió llegar a la cosmovisión de las clases populares.

La misma necesidad de resistencias fue exhibida por el joven sastre Torres cuando indignado por la desgracia de la inequidad entre pobres y ricos de su pueblo, comandó una revuelta para ingresar al parque central donde los ricos hacían su "domingo de gala", y se prohibía la entrada a los pobres. Al respecto Torres escribió:

Se fijaron carteles y se distribuyeron volantes invitando a las gentes descalzas y de ruana, a las madres pobres con sus hijos, a los mendigos, a la masa en general, a tomarse el parque a la hora de la inauguración y el pueblo acudió [...] Aterrados los nuevos ricos abandonaron el lugar, y nosotros los organizadores de la protesta retuvimos los músicos para que cumplieran su programa. (TORRES, 2004, p. 42-43)

Con constancia y resistencia, los dos sastres exigieron el respeto a la libertad en los diversos espacios sociales, y lucharon contra la imposición de los ritmos temporales que deshumanizaba a los obreros. Tanto Coutinho como Torres participaron en la organización de las asociaciones mutuales para el placer y ayuda de los obreros, y más importante, 
participaron en la organización de Partidos Socialistas que "protegessem os operários dos abusos patronais e promovessem a sua politização" (SCHMIDT, 2000, p.119).

Las ideas de unión solidaria, educación y resistencia hicieron parte fundamental de las personalidades de los líderes obreros aquí estudiados, y, progresivamente, se infiltraron en sus acciones, convirtiendo a pequeños sastres artesanos en ideólogos y portavoces de una tendencia mundial. Torres peregrinó por Colombia llevando a los oídos de los obreros y los sectores populares la "luz" de la lucha revolucionaria, fundó periódicos obreros y siempre tuvo la sólida convicción de que el estudio de la realidad era un factor indispensable para la transformación social y la búsqueda de la libertad. Por su parte, Coutinho, una década antes, afirmó con convicción que "O nosso fim é inteiramente utilitário, visa o despertamento e educação social das classes operárias”17, y apoyó directamente la consolidación del Partido Socialista en Rio Grande.

IV

Ahora debemos hablar de las diferencias, con el fin de acentuar las semejanzas entre los dos líderes obreros. Evidentemente los contextos en los que desenvolvieron sus trabajos fueron distintos. Mientras que Brasil vivió un período de leve industrialización, a finales del siglo XIX, que produjo una "precoz" aparición de la clase obrera, en Colombia este proceso de precaria industrialización solo se llevó a cabo durante la segunda década del siglo XX, lo que matizó la aparición de una clase obrera definida. Otra distinción fue el papel que jugó la fuerza de trabajo inmigrante al interior de la clase obrera. En Colombia, los inmigrantes no alcanzaron a ser el 1\% de la población, mientras que, solo en el estado de Rio Grande do Sul, para 1920 había un total de 20.286 inmigrantes, cerca del $11 \%$ de la población del estado (LOVE, 1997), no podemos olvidar que el mismo Coutinho hizo parte de esa población inmigrante.

Otro aspecto que aleja a nuestros sastres fue su escolaridad. En cuanto Coutinho recibió alguna educación en Portugal antes de salir rumbo a Brasil, y desde muy joven expresaba un gusto por la lectura (SCHMIDT, 2000); Torres nunca estudió en una escuela formal, lo que generó que, "tal vez impulsado por su complejo de ignorancia, se transformase desde temprano en un ávido lector y un prolífico escritor" (ARCHILA, 2004, p. 358). En esta distinción entre los procesos formativos de los dos sastres, podemos encontrar un punto de

${ }^{17}$ O Tempo, 23-5-1907, (Apud, SCHMIDT, 2000, p.154). 
contacto determinado por la producción y las características de sus trabajos. Para los dos líderes la disciplina era parte esencial en su proceso de formación. Su disciplina en el estudio de la realidad social los llevó a largas horas de estudio -autodidacta-, sacrificios, discusiones interminables y a la búsqueda de nuevas fuentes de estudio de las ideas socialistas. Para el caso de Coutinho sus relacionamientos con reconocidos intelectuales argentinos - como José Ingenieros- le permitieron acceder a las últimas discusiones del momento ${ }^{18}$, y Torres, en el contacto con los talleres artesanales y algunos poetas colombianos de renombre - como Guillermo Valencia- encontró bibliotecas que le ofrecieron algunas lecturas literarias y teóricas que formaron su carácter ${ }^{19}$.

Esta disciplina "académica" permitió que los sastres formaran una perspectiva particular de las ideas socialistas de la época. En 1907, por ejemplo, Coutinho defendió que el "socialismo era orientado pelas "leis científicas da historia", ${ }^{20}$, perspectiva que per-se lo dotaron de razón científica. De la misma forma, en 1916, en el primer número del periódico La Humanidad, Torres se declaró heredero del gesto vindicador de Bakunin -demostrando además las contradicciones teóricas propias del período-, y siempre buscó la creación de un partido obrero que reivindicara el papel de clase dentro del proletariado. Confiados en un futuro que traería una sociedad libre bajo las leyes científicas, los dos sastres asumieron su papel como guías ideológicas para la libertad de las clases populares.

Aunque no se puede afirmar que Torres y Coutinho fueron iguales, son más las semejanzas en sus recorridos por el mundo obrero que los puntos que los alejan. Precisamente lo que nos permite unir espacios y tiempos distantes en una misma noción de mundo son las ideas de izquierda, y en especial la idea de libertad reflejada en el afán de educar al pueblo e incentivar la solidaridad y la resistencia de clase. Es esta idea fuerza la que permite al historiador transgredir las fronteras espaciales y temporales, con el fin de entender las fuerzas que impulsaron las luchas de los hombres.

De este modo, las ideas permitieron construir un mundo de posibilidades que dieron sentido a la resistencia de algunos sectores populares y obreros comprometidos con la trasformación de sus condiciones de existencia. La unión solidaria, la educación, la humanidad, la revolución y sobre todo la libertad fueron las herramientas, utilizadas por nuestros sastres ideólogos, para proponer otros horizontes de sentido. Detrás de los discursos

\footnotetext{
${ }^{18}$ Antonio Guedes Coutinho publicó en el periódico Echo Operário, dirigido por él, una comunicación con el intelectual argentino José Ingenieros, en la que le agradecía el envío de diverso material educativo, entre los que se encontraban textos de Lafargue, Plecanow, Turati, Tolstoy, J.B. Justo, Ruben Dario, Macedonio Fernández, entre otros (Apud PETERSEN,1992, p.113)

19 Ver Torres $(2005 ; 2004)$

${ }^{20}$ O Tempo, 23-5-1907, (Apud SCHMIDT, 2000, p.81)
} 
pasionales, en ocasiones autoritarios y pedantes, se encontraban las lecturas realizadas con esfuerzo y disciplina, desde Benoít Malon, Karl Marx, Federico Engels, Jean Jaurés hasta Lamartine, todos fueron leídos -esto no quiere decir que comprendidos- desde el más acá de la realidad latinoamericana. Y de manera homóloga, las resistencias, como sostiene Scott (2003), fueron entregadas a los "mártires revolucionarios" quienes dejaron de ser escritores y teóricos, para encarnar los sentimientos y deseos de construir una tradición revolucionaria. Jean Jaurés, por ejemplo, fue definido por Coutinho como un apóstol socialista que sabía representar y honrar la causa ${ }^{21}$, y en 1914 después de su muerte, Torres tomó la decisión, como ya mencioné, de adherirse al movimiento mundial de izquierda y se declaró devoto de sus ideas (TORRES, 2005, p.7; 2004, p.28).

Las esperanzas y resistencias que movilizan a las masas, en cualquier momento histórico, constituyen el Utillaje Mental desde el cual estas entienden el mundo. Es decir, constituyen "el conjunto de aspiraciones, de sentimientos e ideas que reúnen los miembros de un grupo social y los opone a otros grupos" (CHARTIER, 1992). Éste Utillaje Mental solo puede ser consolidado en la compleja relación de esas aspiraciones, sentimientos e ideas, con las prácticas rutinarias de los individuos. Es por esta razón que los espacios y los tiempos pueden ser aproximados en el ejercicio del historiador, ya que, en el fragor de la deshumanización creada por las relaciones capitalistas de producción, vividas por los protagonistas de esta historia, por ejemplo, las rutinas de las clases obreras y de los artesanos y campesinos, permitieron el intercambio de ideas que posibilitaron la constitución de un Utillaje Mental común, desde el cual se creía que la realidad podía ser modificada.

De esta manera, las ideas ya no pueden ser abordadas como estructuras apartadas de los contextos, sino que deben ser entendidas dentro de su relación con los mundos vividos por los sujetos. En el mundo de las clases populares y obreras de principios del siglo XX, las ideas teóricas se mezclaron con un lenguaje religioso y cotidiano para convertirse en un lenguaje comprensible a los oídos populares. Tanto Torres como Coutinho, crearon Utillajes Mentales, herramientas con las que el movimiento obrero y popular luchó por sus derechos. Siguiendo al profesor Thompsom (1987), se podría decir que esa lucha se constituyó en una cultura intelectual en la que la "consciencia articulada del autodidacta era, sobre todo, una consciencia política” (p. 303).

En conclusión, la idea de libertad, encarnada en el mundo vivido por las clases populares y proletarias, permite conectar espacios distantes por medio de su historia escrita.

${ }^{21}$ Echo Operario, 27-3-1898, p1, (Apud SCHMIDT, 2000, p.87). 
De esta manera, se pueden comparar rupturas e continuidades dentro de los movimientos obrero-populares de América Latina, sin olvidar que las ideas aparecen, se conectan y se transforman según los intereses de quien las pone en acción. Tanto para Coutinho como para Torres, el socialismo fue una forma de reivindicar los derechos de los trabajadores, por eso fue tan importante la crítica, la educación y la toma de consciencia para la resistencia aunque esto no significa que sus acciones hayan tenido éxito-. Así, siguiendo a Marx, la crítica -propia de los dos sastres- deshojó las flores imaginarias de la cadena, no para que el hombre arrastrara la cadena que no estaba embellecida por la fantasía, sino para que arrojara de sí esa esclavitud y recogiera la flor viviente (MARX, 1843/2011, p. 146). Fue esta lógica la que determinó el trabajo de nuestros sastres y posibilitó su formación como ideólogos.

\section{REFERÊNCIAS BIBLIOGRÁFICAS}

AGUILERA, Mario \& VEGA, Renan. Ideal Democratico y Revuelta Popular. Bogotá: CEREC. 1998.

ARCHILA, N. Mauricio. Cultura e identidad Obrera en Colombia. Bogotá: Cinep. 1991.

ARCHILA, Mauricio. Ignacio Torres Giraldo, Anecdotario. Cali: Universidad del Valle, 2004, 243 páginas. Anuario Colombiano de Historia Social y Cultural. Reseñas. Volumen 30, 2004.

ARCHILA, N. Mauricio. La humanidad, el periódico obrero de los años veinte. Boletín Cultural y Bibliográfico. Número 3, Volumen 22, p.19-33. 1985

BARTZ, Federico. O Horizonte Vermelho: o impacto da revolução russa no movimento operário do Rio Grande do Sul 1917- 1920. Dissertação de mestrado apresentada ao PPemH da UFRGS, 2008.

BERLIN, isaiah. Dos conceptos de libertad. 1958. Disponibles en http://www.google.com.br/url?sa=t\&rct=j\&q=\&esrc=s\&source=web\&cd=1\&ved=0CCEQFj AA\&url=http $\% 3 \mathrm{~A} \% 2 \mathrm{~F} \% 2 \mathrm{Fwww}$.liberallibertario.org\%2Fhome $\% 2$ Findex.php $\% 2 \mathrm{Fdocument}$ os-partidarios\%2Fdoc_download\%2F168-isaiah-berlin-dos-conceptos-de libertad\&ei=Vt2hU831GMeaqAb7mIG4BQ\&usg=AFQjCNE5ZUKqUzUfKAKWahCOteRzRq3BQ\&bvm=bv.69137298,d.b2k> Aceso el: 13 julio de 2011

BERLIN, isaiah. Quatro ensaios sobre a liberdade. Brasília: Univ de Brasília. 1981.

BILHÃO, Isabel. Rivalidades e Solidariedades no Movimento Operário ( Porto Alegre 19061911). Porto Alegre: EDIPUCRS, 1999. 
CHARTIER, Roger. El Mundo Como Representación. Barcelona: Gedisa Editoria,1992.

TORRES, G. Ignacio. Anecdotario. Cali: Universidad del Valle Programa Editorial. 2004.

TORRES, G. Ignacio. Cincuenta meses en Moscú. Cali: Universidad del Valle Programa Editorial. 2005.

GUTIERREZ, D. Emilio. Ignacio Torres Giraldo y su Participación en la Política de Pereira. Revista Gestión \& Región. Número.6, 2008.

LOVE, Joseph. O Rio Grande do Sul como fator de instabilidade na República Velha. Em: FAUSTO Boris (Coor) HISTORIA DA CIVILIZAÇÃO BRASILEIRA. III. O Brasil Republicano 1. Estrutura De Poder Economia (1889-1930). São Paulo: Defil,1997.

LOVEJOY, Arthur. The Great Chain of Being: A Study of the History of an Idea. Harvard University Press, 1936.

MARX, Karl. Critica da filosofia do direito de Hegel. São Paulo: Boitempo, 2 edição revistada, 2011.

NOVAES, Adauto. (Org.) O avesso da Liberdade. São Paulo: Companhia das letras. 2002.

NÚÑEZ, Luz Ángela. El Obrero Ilustrado: Prensa Obrera y Popular en Colombia 19091924. Bogotá: Uniandes-Ceso. 2006.

PETERSEN, Silvia \& LUCAS, Maria. Antologia do Movimento Operário Gaúcho. 18701937. Porto Alegre: Editora da UFRGS/tchei. 1992.

SCHMIDT, B. Benito. Um socialista no Rio Grande do Sul Antonio Guedes Coutinho (18681945). Porto Alegre: Editora da Universidade. 2000.

SCHMIDT, B. Benito. Uma reflexão sobre o gênero biográfico: a trajetória do militante socialista Antonio Guedes Coutinho na perspectiva de sua vida cotidiana (1868-1945). Porto Alegre: Dissertação de Mestrado em Historia UFRGS. 1996.

SCOTT, James. Los dominados y el arte de la resistencia. Tafalla: Editorial Txalapata. 2003

THOMPSON, P. Edward. A formação da Classe Operária Inglesa: Aforça dos trabalhadores. São Paulo: Paz e Terra, V.III, 1987.

Oficina do Historiador, Porto Alegre, EDIPUCRS, v. 7, n. 2, jul./dez. 2014, p. 155-172. 
VEGA, Renan. Gente muy Rebelde (4 t) Bogotá: , Editorial Pensamiento Crítico. 2002

WALICKI, Andrzej. Karl Marx como filosofo de la libertad. Critical Review. vol. 2 Numero: 4. 1998 